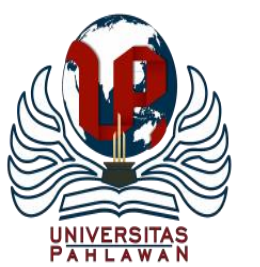

Jurnal Basicedu Volume 4 Nomor 2 April 2020 Hal.371-378

JURNAL BASICEDU

Research \& Learning in Elementary Education

https://jbasic.org/index.php/basicedu

\title{
Efektivitas Problem Based Learning dan Guided Inquiry Learning Terhadap Kemampuan Berpikir Kritis Siswa Sekolah Dasar
}

\author{
Siti Khomaidah ${ }^{1}$, Henny Dewi Koeswanti ${ }^{2}$ \\ Universitas Kristen Satya Wacana, Jawa Tengah, Indonesia \\ E-mail 292016045@student.uks.eduㄹ.
}

\begin{abstract}
Abstrak
Tujuan dari penelitian ini adalah untuk mengetahui efektifitas model Problem Based Learning dengan Guided Inquiry Learning terhadap kemampuan berpikir kritis siswa kelas 5 SD. Sampel yang digunakan dalam penelitian ini adalah siswa kelas 5 SD Negeri Tingkir Tengah 01 yang berjumlah 29 siswa, dan SD Negeri Tingkir Tengah 02 yang berjumlah 32 siswa. Teknik pengumpulan data berupa tes pilihan ganda. Analisis data yang digunakan berupa teknik analisis uji t yang digunakan untuk mengetahui perbedaan rata-rata antara kelompok yang menggunakan model Problem Based Learning dan Guided Inquiry Learning. Pengujian hipotesis menggunakan independent sample $T$ test dengan signifikansi pada kolom sig. (2-tailed) sebesar $0,006<0,05$ dengan hasil $\mathrm{t}_{\text {hitung }}$ sebesar 2,832 $>\mathrm{t}_{\text {tabel }} 2,001$, maka $\mathrm{H}_{0}$ ditolak yang berarti terdapat efektivitas kemampuan berpikir kritis antara kelompok yang menggunakan model Problem Based Learning dengan Guided Inquiry Learning. Hal ini dapat dilihat dari nilai rata-rata kelompok Problem Based Learning sebesar 79,37 dan kelompok model Guided Inquiry Learning nilai rata-rata posttest 75,63. Hal ini menunjukan bahwa model Problem Based Learning lebih efektif di bandingkan dengan model Guided Inquiry Learning terhadap kemampuan berpikir kritis siswa kelas 5 SD Gugus Joko Tingkir Salatiga Tahun Pelajaran 2019/2020.
\end{abstract}

Kata Kunci: Problem Based Learning, Guided Inquiry Learning, dan Kemampuan Berpikir Kritis

\begin{abstract}
The purpose of this research is to know about effectiveness of Problem Based Learning model and Guided Inquiry Learning model to critical thinking skills of 5th grade elementary school students. The sample used in this research is grade 5 students of tingkir tengah 01 elementary school with the total 29 students and tingkir tengah 02 elementary school with the total 32 students. Data collection techniques is multiple choice test. Analysis of the data used is T-Test that used to know about difference of everage groups using problem based learning and Guided Inquiry Learning models. Hypothesis testing uses independent sample $\mathrm{T}$ tests with significance in the sig column. (2-tailed) of $0.006<0.05$ with a count of $2.832>$ table 2.001 , then $\mathrm{H}_{0}$ is rejected, which meant there were effectiveness in critical thinking skills between groups using the Problem Based Learning model with Guided Inquiry Learning. This can be seen from the average value of the Problem Based Learning group of 79.37 and the Guided Inquiry Learning model group's average posttest score of 75.63. This showed that the Problem Based Learning model is more effective than the Guided Inquiry Learning model for the critical thinking skills of 5th grade students of the Joko Tingkir Salatiga Cluster in the 2019/2020 Academic Year.
\end{abstract}

Keywords: Problem Based Learning, Guided Inquiry Learning, and Critical Thinking Skills

@ Jurnal Basicedu Prodi PGSD FIP UPTT 2020

$\triangle$ Corresponding author :

Address : Kemiri Raya no 7

Email : 292016045@student.uksw.edu

ISSN 2580-3735 (Media Cetak)

Phone

ISSN 2580-1147 (Media Online) 


\section{PENDAHULUAN}

Pendidikan Sekolah Dasar merupakan pendidikan yang ditempuh oleh siswa sebagai landasan dan bekal bagi pendidikan Sekolah Menengah Pertama maupun Sekolah Menengah Atas (Peraturan Pemerintah Republik Indonesia Nomor 17 Tahun 2010 Tentang Pengelolaan dan Penyelenggaraan Pendidikan). Perangkat pendidikan yang dapat digunakan untuk mencapai tujuan pembelajaran yaitu kurikulum. Kurikulum yang digunakan dalam pendidikan Indonesia adalah Kurikulum 2013. Tujuan dari Kurikulum 2013 yaitu siswa mampu berpikir kritis, inovatif, produktif, dan berkarakter. (Permendikbud No.69 Tahun 2013 Tentang Kerangka Dasar dan Struktur Kurikulum Sekolah Menengah Atas/ Madrasah Aliyah). Tujuan kurikulum dapat tercapai dengan bantuan guru dalam kegiatan pembelajaran.

Kegiatan pembelajaran dapat dikatakan berhasil, apabila siswa dapat memahami materi pembelajaran. Hal ini yang menuntut guru untuk mempunyai kompetensi pedagogik. Kompetensi pedagogik merupakan kemampuan yang dimiliki seseorang pada kegiatan mengajar. Aspek yang diperlukan guru agar mempunyai kompetensi pedagogik yang baik yaitu aspek yang terkait dengan ilmu mendidik, mempunyai keterampilan dasar pada kegiatan mengajar, dan mampu mengelola kelas agar tercipta lingkungan belajar yang kondusif dan efektif, sehingga dapat mencapai tujuan pembelajaran (Indriani, 88: 2015).

Guru dalam mencapai tujuan pembelajaran harus mampu menguasai materi dengan baik. Materi pembelajaran yang terkandung dalam Tema 7, Subtema 1, pembelajaran 1 Kelas 5 yaitu Bahasa Indonesia tentang informasi penting dalam teks narasi sejarah, IPS tentang kedatangan bangsa Eropa ke Indonesia, Ilmu Pengetahuan Alam tentang sifat-sifat benda padat,cair, dan gas. Bahasa Indonesia merupakan bahasa yang digunakan pada dokumen-dokumen resmi negara. Bahasa Indonesia mempunyai peran penting yaitu dalam keterampilan berkomunikasi dan penguasaan ilmu pengetahuan (Agustin, 2011: 256-257).

Ilmu Pengetahuan Sosial yaitu konsep yang mengembangkan aspek pengetahuan, sikap, dan keterampilan sosial agar dapat membentuk pribadi warga negara yang baik. (Manfajri,\&Yolvena, 2019:796). Hal ini berbeda dengan Ilmu Pengetahuan Alam yang mempunyai pengertian bahwa mata pelajaran yang wajib diajarkan kepada siswa, karena dapat melatih berpikir logis atau rasional. Siswa dapat memahami materi pembelajaran dengan baik karena siswa belajar melalui pengalaman secara langsung, hal ini dapat berpengaruh terhadap kecerdasan intelektual siswa (Astari, dkk, 2018: 2).

Kecerdasan intelektual dapat dilatih menggunakan model-model pembelajaran yang sesuai dengan aspek kemampuan berpikir kritis. Dapat dilihat dalam Permendiknas 81A Tahun 2013 tentang Implemetasi Kurikulum yang menjelaskan bahwa siswa yang diperlukan dimasa depan yaitu harus mempunyai keterampilan berkomunikasi, mampu berpikir kritis, mampu berpikir kreatif yang sesuai dengan nilai dan moral pancasila agar menjadi warga negara yang dapat bertanggung jawab, demokratis, mempunyai rasa toleransi, mampu bersosialisasi dengan masyarakat, dan peduli pada lingkungan sekitar. Tugas guru dalam kegiatan pembelajaran harus mampu melatih siswa untuk berpikir kritis, sehingga tidak hanya hasil belajar yang menjadi aspek terpenting.

Berpikir kritis mempunyai tujuan yaitu agar siswa mampu menalar materi pembelajaran, kreatif, produktif, kritis, mandiri, kolaboratif, dan komunikatif (Peraturan menteri Pendidikan Nasional No 22 Tahun 2016) Kemampuan berpikir kritis yang dimiliki oleh siswa di Indonesia tergolong rendah, hal ini terbukti dari hasil Trends in International Mathematick and Science Study 2015 (Azizah, dkk, 2018: 62) yang 
menjelaskan bahwa Indonesia menduduki peringkat ke 45 dari 50 negara pada muatan matematika. Pada kegiatan literasi dilihat dari PISA Indonesia menduduki peringkat ke 64 dari 65 negara. Rendahnya literasi dapat diketahui dari hasil tes yang dilaksanakan pada tahun 2012 yaitu 328 dan grafik yang menunjukan tidak terdapat peningkatan nilai pada literasi sains siswa di Indonesia pada tahun 2006, 2009, dan 2012 menurut OECD (Supriatna \& Yuliariatiningsi, 2011:382). Penjelasan tersebut didukung oleh hasil penelitian yang menjelaskan bahwa siswa di Indonesia belum siap dalam menerima soalsoal literasi yang menuntut siswa agar dapat berpikir kritis khususnya di kecamatan kutawaringin. Siswa merasa kesulitan pada saat mengerjakan soal literasi, karena siswa sudah terbiasa mengerjakan soal yang berisi tentang pemahaman konsep (Supriatna \& Yuliariatiningsi, 2011:382).

Penelitian tentang rendahnya kemampuan berpikir kritis juga dilakukan oleh Budiartini (2013:3) yang menjelaskan bahwa hasil wawancara yang dilakukan di SD N 7 Datah mengalami penuruan hasil belajar pada muatan Ilmu Pengetahuan Alam. Penuruanan hasil belajar disebabkan oleh pembelajaran yang kurang melatih siswa untuk berpikir kritis. Penelitian Budiana (2013: 1-4) mengemukakan bahwa presentase skor masing-masing yang diperoleh siswa pada tahap berpikir kritis kurang dari $40 \%$.

Berdasarkan permasalahan tentang rendahnya kemampuan berpikir kritis, maka dalam kegiatan pembelajaran guru harus mampu menggunakan model-model pembelajaran yang dapat melatih siswa untuk berpikir kritis. Model pembelajaran yang dapat digunakan yaitu model Problem Based Learning dan Guided Inquiry. Model Problem Based Learning merupakan metode inovatif yang digunakan pada pembelajaran dan berpusat pada siswa yang dapat berpengaruh terhadap keafktifan belajar siswa (Koeswanti, 2018:67)
Model pembelajaran yang sejalan dengan Problem Based Learning yaitu model pembelajaran Guided Inquiry. Pembelajaran menggunakan model Guided Inquiry menuntut siswa untuk menyelesaikan masalah yang diberikan oleh guru. Tugas guru yaitu tidak hanya sebagai pemberi materi pembelajaran secara utuh, tetapi guru bertugas memancing siswa agar dapat melakukan sesuatu untuk menyelesaikan masalah. Model Guided Inquiry Learning menuntut siswa dapat menyelesaikan masalah secara mandiri dengan bimbingan guru, sehingga siswa tidak mendengarkan ceramah guru (Anam, 2016:17)

Persamaan model Problem Based Learning dengan model Guided Inquiry Learning yaitu sama-sama menggunakan masalah dalam kegiatan pembelajaran. Tidak hanya terdapat persamaan, tetapi juga terdapat perbedaan yaitu pada model Problem Based Learning guru menyajikan masalah yang terdapat dalam kehidupan nyata. Pada model Guided Inquiry siswa mengajukan pertanyaanpertanyaan yang berhubungan dengan masalah, dan untuk menjawab pertanyaan dengan benar siswa melakukan kegiatan penyelidikan dengan bimbingan guru. Kegiatan penyelidikan yang dilakukan oleh siswa mempunyai tujuan yaitu agar siswa dapat mengumpulkan informasi atau data tentang permasalahan (Tiya Rahmawati, 2019: 23-24).

Penelitian Diani, dkk (2016). Perbandingan Model Pembelajaran Problem Based Learning dan Inkuiri Terbimbing Terhadap Kemampuan Berpikir Kritis Peserta Didik. Hasil penelitian menunjukan model Problem Based Learning dan Guided Inquiry berpengaruh terhadap kemampuan berpikir kritis dengan uji $\mathrm{t}$ hitung $>\mathrm{t}$ tabel atau 2,03>1,99 sehingga $\mathrm{H}_{0}$ ditolak. Dapat disimpulkan bahwa kelas eksperimen I dengan eksperimen II terdapat perubahan.

Hal ini sejalan dengan penelitian Putri (2018) Studi Komparatif Metode Guided Inquiry Learning dan Metode Problem Based 
Learning terhadap Kemampuan Berpikir Kritis Siswa. Hasil penelitian menunjukan bahwa model Problem Based Learning dan Guided Inquiry berpengaruh terhadap kemampuan berpikir kritis siswa yaitu nilai signifikan 0,000 lebih kecil jika dibandingkan dengan nilai alpha 0,05 , ini berarti Ha diterima dan $\mathrm{H}_{0}$ ditolak.

Berdasarkan latar belakang, maka dapat dipertimbangkan akan pentingnya dilakukan penelitian "Efektivitas Problem Based Learning - Guided Inquiry Learning Tema 7 Subtema 1 Terhadap Kemampuan Berpikir Kritis Siswa Kelas 5 Semester 2 Tahun 2019/2020.

\section{METODE}

Penelitian ini menggunakan jenis penelitian eksperimen semu. Sugiyono (2012:114) mengemukakan bahwa penelitian ekserimen semu (Quasi Eksperimental Research) merupakan desain penelitian yang digunakan untuk mengontrol variabel-variabel luar yang dapat mempengaruhi penelitian.Tujuan dari penelitian ini agar dapat mengetahui efektivitas pembelajaran menggunakan model Problem Based Learning dan Guided Inquiry terhadap kemampuan berpikir kritis siswa kelas 5. Desain penelitian yang digunakan adalah Postest Only Control Design.

Populasi dalam penelitian ini yaitu SD Gugus Joko Tingkir Salatiga yang terdiri dari 5 SD yang mempunyai kesetaraan. Sampel yang digunakan dalam penelitian ini dipilih secara acak yaitu SD Negeri Tingkir Tengah 02 Salatiga sebagai kelas eksperimen yang menggunakan model Problem Based Learning. dan SD Negeri Tingkir Tengah 01 Salatiga sebagai kelas kontrol yang menggunakan model Guided Inquiry Learning. Subjek yang diambil yaitu siswa kelas 5 di SD Negeri Tingkir Tengah 01 yang terdiri dari 29 siswa dan SD Negeri Tingkir Tengah 02 yang terdiri dari 32 siswa.
Kegiatan yang dilakukan sebelum penelitian yaitu melakukan validitas soal yang dilaksanakan pada tanggal 12 Februari 2020 di SD Negeri Tingkir Lor 02 yang terdiri dari 32 siswa. Penelitian dilaksanakan pada tanggal 28 Februari 2020 di SD Negeri Tingkir Tengah 01 dan pada tanggal 26 Februari 2020 di SD Negeri Tingkir Tengah 02 Salatiga. Variabel yang digunaan dalam penelitian ini yaitu variabel bebas dan terikat. Pada variabel bebas menggunakan model Problem Based Learning $\left(X_{1}\right)$ dan Guided Inquiry $\left(X_{2}\right)$ dan yang menjadi variabel terikat yaitu kemampuan berpikir kritis $(Y)$.

Teknik pengumpulan data yang digunakan dalam penelitian ini berupa teknik tes. Teknik tes merupakan teknik pengukuran yang menggunakan pertanyaan-pertanyaan, atau tugas yang harus dijawab atau diselesaikan oleh subjek (Arifin, 2011: 226). Teknik tes digunakan untuk mengetahui kemampuan berpikir kritis siswa dalam bentuk tes pilihan ganda. Hal ini berbeda dengan analisis data yang menggunakan analisis data deskriptif sebagai uji persyarat yang terdiri dari uji normalitas, dan homogenitas. Hal ini dilakukan sebelum melakukan uji beda (t) yang digunakan untuk mengetahui perbedaan rata-rata yang menggunakan model Problem Based Learning dengan Guided Inquiry Learning.

\section{HASIL DAN PEMBAHASAN}

Analisis data yang digunakan untuk menguji prasarat yaitu diskripsi kuantitatif. Analisis Diskriptif menggunakan SPSS 20 for Windows. Tujuan dari menggunakan analisis diskriptif yaitu untuk mengetahui perbedaan hasil belajar siswa yang menggunakan model Problem Based Learning dengan kelompok yang menggunakan model Guided Inquiry Learning. 
Berikut merupakan hasil analisis menggunakan SPSS 20 For Windows.

Tabel 1: Deskriptrive Statistic PBL

\section{Descriptive Statistics}

\begin{tabular}{|c|c|c|c|c|c|}
\hline & $\mathrm{N}$ & $\begin{array}{c}\text { Mini } \\
\mathrm{mu} \\
\mathrm{m}\end{array}$ & $\begin{array}{c}\text { Max } \\
\text { imu } \\
m\end{array}$ & Mean & $\begin{array}{l}\text { Std. } \\
\text { Devi } \\
\text { ation }\end{array}$ \\
\hline Posttest PBL & 32 & 67 & 90 & 79,37 & 5,450 \\
\hline $\begin{array}{l}\text { Valid N } \\
\text { (listwise) }\end{array}$ & 32 & & & & \\
\hline
\end{tabular}

Berdasarkan hasil analisis Diskriptif, Nilai ratarata yang menggunakan model Problem Based Learning yaitu 79,37 dengan standar deviasi 5,450. Perolehan nilai tertinggi pada model Problem Based learning 90 dan nilai terendah 67.

Tabel 2: Deskriptrive Statistic Guided Inquiry Learning

\begin{tabular}{lc|c|c|c|c}
\multicolumn{7}{c}{ Descriptive Statistics } \\
& & $\begin{array}{c}\text { Mini } \\
\text { mu }\end{array}$ & $\begin{array}{c}\text { Max } \\
\text { imu }\end{array}$ & & $\begin{array}{c}\text { Std. } \\
\text { Devi } \\
\end{array}$ \\
& $\mathrm{N}$ & $\mathrm{m}$ & Mean & ation \\
\hline $\begin{array}{l}\text { Posttest } \\
\text { GuidedInquiry }\end{array}$ & 29 & 63 & 83 & 75,63 & 4,806 \\
Learning & & & & & \\
\hline $\begin{array}{l}\text { Valid N } \\
\text { (listwise) }\end{array}$ & 29 & & & & \\
\hline
\end{tabular}

Berdasarkan hasil analisis Diskriptif, Nilai rata-rata yang menggunakan model Guided Inquiry Learning yaitu 75,63 dengan standar deviasi 4,806. Perolehan nilai tertinggi pada model Guided Inquiry Learning 83 dan nilai terendah 63

Tabel 3.

Hasil Pengukuran Kemampuan Berpikir Kritis

\begin{tabular}{|c|c|c|c|}
\hline $\begin{array}{c}\text { Pengukura } \\
\mathrm{n}\end{array}$ & \multicolumn{2}{|c|}{ Rata-rata Skor (Mean) } & $\begin{array}{c}\text { Selisi } \\
\mathrm{h}\end{array}$ \\
\cline { 2 - 3 } & $\begin{array}{c}\text { Problem } \\
\text { Based } \\
\text { Learning }\end{array}$ & $\begin{array}{c}\text { Guided } \\
\text { Inquiry } \\
\text { Learning }\end{array}$ & \\
\hline Posttest & 79,37 & 75,63 & 3,74 \\
\hline
\end{tabular}

Berdasarkan hasil data diatas, maka dapat disimpulkan bahwa rata-rata hasil posttest kelompok yang diberikan perlakuan dengan model
Problem Based Learning dan model Guided Inquiry Learning mempunyai selisish 3,74. Hal ini dapat dilihat dari diagram dibawah ini:

Gambar 1. Diagram Berpikir Kritis

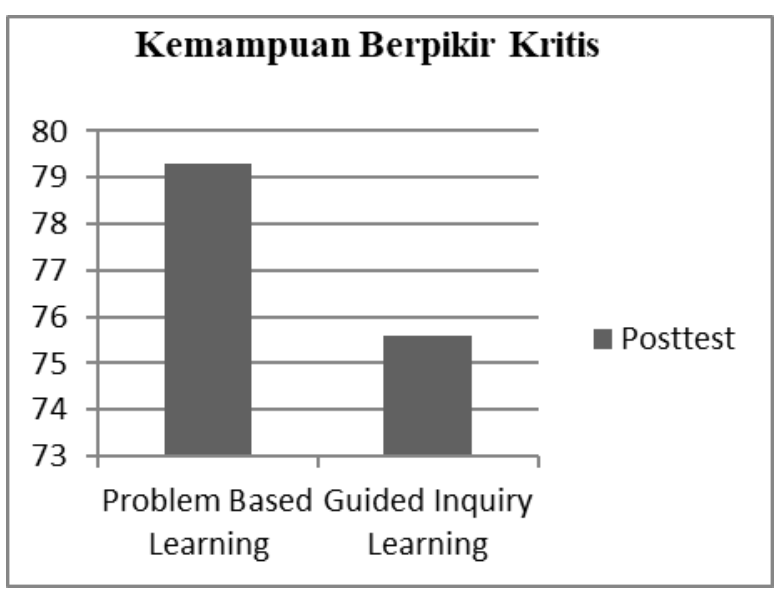

Penelitian ini menggunakan uji normalitas dengan teknik Shapiro-wilk menggunakan SPSS 20 for Windows. Uji normalitas untuk mengetahui datanya terdistribusi normal atau tidak. Nilai signifikasi/probabilitas dapat dikatan berdistribusi normal apabila $>0,05$ dan nilai signifiaksi/probalitas $<0,05$ maka data tidak berdistribusi normal.

Tabel 4. Uji Normalitas

\begin{tabular}{|c|l|r|r|r|}
\multicolumn{4}{c}{ Tests of Normality } \\
\hline \multirow{2}{*}{} & kelas & \multicolumn{3}{|c|}{ Shapiro-Wilk } \\
\cline { 3 - 5 } & & $\begin{array}{c}\text { Stati } \\
\text { stic }\end{array}$ & Df & Sig. \\
\hline $\begin{array}{l}\text { kema } \\
\text { mpuan } \\
\text { berpiki } \\
\text { r kritis }\end{array}$ & $\begin{array}{l}\text { Posttest } \\
\text { PBL } \\
\text { Guided } \\
\text { Inquiry }\end{array}$ & .964 & 32 & .353 \\
\hline
\end{tabular}

a. Lilliefors Significance Correction

Berdasarkan hasil normalitas dengan menggunakan Shapiro Wilk, dapat dilihat tingkat signifikansi pada nilai posttest pada kelompok eksperimen yang menggunakan model Problem Based Learning yaitu 0,353>0,05 yang artinya berdistribusi normal, sedangkan kelompok yang menggunakan model Guided inquiry Learning 
yaitu $0,110>0,05$ yang artinya berdistribusi normal.

Tidak hanya menggunakan Uji normalitas, dalam penelitian ini juga menggunakan uji Homogenitas. Tujuan homogenitas yaitu untuk mengetahui data apakah variabel bebes dan terikat dalam penelitian bersifat homogen Jika nilai signifikasi/ probabilitas $>0,05$ maka, dapat dikatan bahwa varian dua kelompok populasi data homogen. Jika nilai signifiakasi atau probabilitas $<0,05$ maka, data dapat dikatakan bahwa varian dua kelompok populasi tidak homogen.

Tabel 5. Uji Homogenitas

\section{Test of Homogeneity of Variance}

\begin{tabular}{|c|c|c|c|c|c|}
\hline & & $\begin{array}{l}\text { Leve } \\
\text { ne } \\
\text { Statis } \\
\text { tic }\end{array}$ & $\begin{array}{l}\mathrm{d} \\
\mathrm{f} \\
1\end{array}$ & $\mathrm{df} 2$ & Sig. \\
\hline \multirow{6}{*}{$\begin{array}{l}\text { kema } \\
\text { mpua } \\
\mathrm{n} \\
\text { berpi } \\
\text { kir } \\
\text { kritis }\end{array}$} & $\begin{array}{l}\text { Based on } \\
\text { Mean }\end{array}$ & .460 & 1 & 59 & .500 \\
\hline & $\begin{array}{l}\text { Based on } \\
\text { Median }\end{array}$ & .476 & 1 & 59 & .493 \\
\hline & Based on & & & & \\
\hline & $\begin{array}{l}\text { Median } \\
\text { and with }\end{array}$ & .476 & 1 & 58.862 & .493 \\
\hline & $\begin{array}{l}\text { adjusted } \\
\text { df }\end{array}$ & & & & \\
\hline & $\begin{array}{l}\text { Based on } \\
\text { trimmed } \\
\text { mean }\end{array}$ & .494 & 1 & 59 & .485 \\
\hline
\end{tabular}

Uji homogenitas pada tabel diatas menggunakan metode Levene's Test. Cara yang digunakan dalam menggunakan metode Levene's Test, dimana memilih satu interpretasi statistik yang berdasarkan pada rata-rata (Based on Mean). Berdasarkan tabel menunjukkan bahwa hasil uji homogenitas sesudah dilakukan perlakuan memperoleh signifikansi 0,500 dimana > $>0,05$ yang berarti bahwa kedua kelompok baik kelompokeksperimen yang menggunakan model Problem Based Learning dan Guided Inquiry Leraning terdapat varian yang sama atau dikatakan homogen.

Berdasarkan pada Uji Prasarat dapat diambil kesimpulan bahwa data berdistribusi normal dan homogen, setelah data berdistribusi normal dan homogen maka di uji beda $(\mathrm{t})$ yang menggunakan independent T test dengan SPSS 20 for Windows. Penelitian ini membuktikan bahwa hasil uji beda nilai posttest dengan menggunakan model Problem Based Learning lebih tinggi dibandingkan dengan menggunakan Guided Inquiry Learning

Tabel 6. Uji T

Independent Samples Test

\begin{tabular}{|c|c|c|c|c|c|c|c|c|c|c|}
\hline & \multicolumn{2}{|c|}{$\begin{array}{l}\text { Levene's } \\
\text { Test for } \\
\text { Equality of } \\
\text { Variances }\end{array}$} & \multicolumn{7}{|c|}{ t-test for Equality of Means } \\
\hline & & \multirow[t]{2}{*}{$\mathrm{F}$} & \multirow[t]{2}{*}{ Sig. } & \multirow[t]{2}{*}{$\mathrm{t}$} & \multirow[t]{2}{*}{ Df } & \multirow[t]{2}{*}{$\begin{array}{l}\text { Sig. } \\
(2 \\
\text { tailed }\end{array}$} & \multirow[t]{2}{*}{$\begin{array}{l}\text { Mean } \\
\text { Differ } \\
\text { ence }\end{array}$} & \multirow[t]{2}{*}{$\begin{array}{l}\text { Std. } \\
\text { Error } \\
\text { Differ } \\
\text { ence }\end{array}$} & \multicolumn{2}{|c|}{$\begin{array}{c}95 \% \\
\text { Confidence } \\
\text { Interval of the } \\
\text { Difference }\end{array}$} \\
\hline & & & & & & & & & Lower & Upper \\
\hline $\begin{array}{l}\text { kem } \\
\text { amp } \\
\text { uan } \\
\text { berpi } \\
\text { kir } \\
\text { kritis }\end{array}$ & $\begin{array}{l}\text { Equal } \\
\text { varianc } \\
\text { es } \\
\text { assume } \\
\text { d } \\
\text { Equal } \\
\text { varianc } \\
\text { es not } \\
\text { assume } \\
\text { d }\end{array}$ & .460 & $\begin{array}{r}.50 \\
0\end{array}$ & $\begin{array}{r}2.83 \\
2 \\
\end{array}$ & $\begin{array}{r}58 . \\
961\end{array}$ & 更 & 3.743 & 1.313 & . & 6.387 \\
\hline
\end{tabular}

Berdasarkan tabel uji Independent t-test maka dapat disimpulkan bahwa pada kolom sig. (2-tailed) sebesar 0,006 <0,05 dengan hasil $t_{\text {hitung }}$ sebesar 2,832 $>\mathrm{t}_{\text {tabel }} 2,001$, maka $\mathrm{H}_{0}$ ditolak yang berarti terdapat efektifitas kemampuan berpikir kritis antara kelompok yang menggunakan model Problem Based Learning dengan Guided Inquiry Learning. 


\section{SIMPULAN}

Berdasarkan hasil penelitian yang telah dilakukan maka dapat disimpulkan bahwa sampel yang digunakan dalam penelitian ini adalah siswa kelas 5 SD Negeri Tingkir Tengah 01 yang berjumlah 29 siswa, dan SD Negeri Tingkir Tengah 02 yang berjumlah 32 siswa. Teknik pengumpulan data berupa tes pilihan ganda. Analisis data yang digunakan berupa teknik analisis uji t yang digunakan untuk mengetahui perbedaan rata-rata antara kelompok yang menggunakan model Problem Based Learning dan Guided Inquiry Learning. . Pengujian hipotesis menggunakan independent sample $T$ test dengan signifikansi pada kolom sig. (2-tailed) sebesar $0,006<0,05$ dengan hasil $t_{\text {hitung }}$ sebesar 2,832 > $\mathrm{t}_{\text {tabel }} 2,001$, maka $\mathrm{H}_{0}$ ditolak yang berarti terdapat perbedaan kemampuan berpikir kritis antara kelompok yang menggunakan model Problem Based Learning dengan Guided Inquiry Learning. Hal ini dapat dilihat dari nilai rata-rata kelompok Problem Based Learning sebesar 79,37 dan kelompok model Guided Inquiry Learning nilai rata-rata posttest 75,63. Hal ini menunjukan bahwa model Problem Based Learning lebih efektif di bandingkan dengan model Guided Inquiry Learning terhadap kemampuan berpikir kritis siswa kelas 5 SD Gugus Joko Tingkir Salatiga Tahun Pelajaran 2019/2020.

\section{DAFTAR PUSTAKA}

Arifin, Z. (2012). Penelitian Pendidikan: Metode dan Paradigma Baru. Bandung:

Remaja Rosdakarya.

Azizah, M., Sulianto, J., \& Cintang, N. (2018). Analisis Keterampilan Berpikir Kritis Siswa Sekolah Dasar Pada Pembelajaran Matematika Kurikulum 2013. Jurnal Penelitian Pendidikan,

Abdurrozak, R., Jayadinata, A. K., \& Isrok'atun. (2016). Pengaruh Model Problem Based Learning terhadap Kemampuan Berargumentasi dan Hasil Belajar Siswa. Jurnal Pena Ilmiah https://doi.org/10.1017/CBO9781107415324. 004

Agustin, Y. (2011). Kedudukan Bahasa Inggris Sebagai Bahasa Pengantar Dalam Dunia Pendidikan. Deiksis.

Analisis Keterampilan Berpikir Kritis Siswa Sekolah Dasar pada Pembelajaran Matematika Kurikulum 2013. (2018). Jurnal
Penelitian PendidikanA \& A

(Semarang).0020

https://doi.org/10.15294/jpp.v35i1.13529

Astari, F. A., Suroso, S., \& Yustinus, Y. (2018).

Efektifitas Penggunaan Model Discovery Learning Dan Model Problem Based Learning Terhadap Hasil Belajar Ipa Siswa Kelas 3 SD. Jurnal Basicedu. https://doi.org/10.31004/basicedu.v2i1.20

Diani, R., Saregar, A., \& Ifana, A. (2017). Perbandingan Model Pembelajaran Problem Based Learning dan Inkuiri Terbimbing Terhadap Kemampuan Berpikir Kritis Peserta Didik. Jurnal Penelitian Pembelajaran Fisika. https://doi.org/10.26877/jp2f.v7i2.1310

Indriani, F. (2015). Kompetensi Pedagogik Mahasiswa Dalam Mengelola Pembelajaran Tematik Integratif Kurikulum 2013 Pada Pengajaran Micro di PGSD UAD Yogyakarta. Junal Profesi Pendidikan Dasar.

Koeswanti，H. D. (2018). Eksperimen Model Kooperatif Learning Dalam Pembelajaran Keterampilan Menulis Karya Ilmiah Mahasiswa Ditinjau Dari Kemampuan Berpikir Kritis. Salatiga: Satya Wacana Universitas Press.

Monfajri, S. W., \& Miaz, Y. (2019). Peningkatan Hasil Belajar Ips Siswa Dalam Pembelajaran Ips Menggunakan Team Games Tournament Di Sekolah Dasar. Jurnal Basicedu.

Peraturan Menteri Pendidikan dan Kebudayaan No. 22 Tahun 2016 Tentang Standar Proses Pendidikan.

Permendiknas 81A Tahun 2013 tentang Implemetasi Kurikulum .

Putri, N. (2018). Studi Komparatif Metode Guided Inquiry Learning dan Metode Problem Based Learning terhadap Kemampuan Berpikir Kritis Siswa. Indonesian Journal of Economics Education, 1(1), 17-30.

Rusman. (2012). Model-model Pembelajaran Mengembangkan Profesionalisme Guru. In Jakarta: Rajawali Pers.

Sugiyono. (2012). Metode Penelitian Pendidikan: Pendekatan Kuantitatif, Kualitatif dan $R \& D$. Bandung: alfabeta.

Suharsimi, A. (2013). Prosedur Penelitian: Suatu Pendekatan Praktik (Edisi Revisi). Jakarta: Rineka Cipta. https://doi.org/10.1017/CBO9781107415324. 004 
378 Efektivitas Problem Based Learning dan Guided Inquiry Learning Terhadap Kemampuan Berpikir Kritis Siswa Sekolah Dasar - Siti Khomaidah, Henny Dewi Koeswanti

Surahman, E., \& Mukminan, M. (2017). Peran guru IPS sebagai pendidik dan pengajar dalam meningkatkan sikap sosial dan tanggung jawab sosial siswa SMP. Harmoni Sosial: Jurnal Pendidikan IPS. https://doi.org/10.21831/hsjpi.v4i1.8660

Tiya Rahmawati, L. U. dan F. R. (2019). Perbandingan Model Problem Based Learning Dan Inkuiri. Jurnal Tradis Kimiya.

Widyaningrum, R. (2012). Model Pembelajaran Tematik Di MI/SD. Cendekia: Jurnal Kependidikan Dan Kemasyarakatan. https://doi.org/10.21154/cendekia.v10i1.405

yuliariatiningsih, S. (2017). pengaruh model brainstorming terhadap kemampuan berpikir kritis pada mata pelajaran ipa. antologi upi, 5(1), 382. 